\title{
PKCס activated by C-MET enhances infiltration of human glioblastoma cells through NOTCH2 signaling
}

\author{
Eunji Hwang ${ }^{1, *}$, Ki-Chun Yoo ${ }^{1, *}$, Seok-Gu Kang ${ }^{2}$, Rae-Kwon Kim ${ }^{1}$, Yan-Hong Cui ${ }^{1}$, \\ Hae-June Lee ${ }^{3}$, Min-Jung Kim${ }^{4}$, Jae-Seong Lee ${ }^{5}$, In-Gyu Kim ${ }^{6}$, Yongjoon Suh ${ }^{1}$, \\ Su-Jae Lee ${ }^{1}$ \\ ${ }^{1}$ Department of Life Science, Research Institute for Natural Sciences, Hanyang University, Seoul, Korea \\ ${ }^{2}$ Department of Neurosurgery, Severance Hospital, Yonsei University College of Medicine, Seodaemun-gu, Korea \\ ${ }^{3}$ Division of Radiation Effect, Korea Institute of Radiological and Medical Sciences, Seoul, Korea \\ ${ }^{4}$ Laboratory of Radiation Exposure \& Therapeutics, National Radiation Emergency Medical Center, Korea Institute of \\ Radiological and Medical Sciences, Seoul, Korea \\ ${ }^{5}$ Department of Biological Sciences, College of Science, Sungkyunkwan University, Seoul, Korea \\ ${ }^{6}$ Department of Radiation Biology, Environmental Radiation Research Group, Korea Atomic Energy Research Institute, \\ Daejeon, Korea \\ *These authors have contributed equally to this work \\ Correspondence to: Su-Jae Lee, e-mail: sj0420@hanyang.ac.kr \\ Yongjoon Suh, e-mail: hiswork@hanmail.net
}

Keywords: PKCd, infiltration, glioblastoma, NOTCH2, C-MET

Received: August 18, 2015 Accepted: December 05, 2015

Published: December 17, 2015

\section{ABSTRACT}

Poor prognosis of glioblastoma (GBM) is attributable to the propensity of tumor cells to infiltrate into the brain parenchyma. Protein kinase C (PKC) isozymes are highly expressed or aberrantly activated in GBM. However, how this signaling node translates to GBM cell invasiveness remains unknown. Here, we report that among PKC isoforms, PKC is strongly associated with infiltration of GBM cells. Notably, PKC enhanced Tyr418 phosphorylation of the non-receptor tyrosine kinase SRC, which in turn activated STAT3 and subsequent NOTCH2 signaling, ultimately leading to GBM cell invasiveness. Furthermore, we showed that PKC $\delta$ was aberrantly activated in GBM cells by C-MET, a receptor tyrosine kinase hyperactivated in GBM. In agreement, inhibition either component in the C-MET/PKCD/SRC/STAT3 signaling axis effectively blocked the NOTCH2 signaling and invasiveness of GBM cells. Taken together, our findings shed a light on the signaling mechanisms behind the constitutive activation of PKCD signaling in GBM.

\section{INTRODUCTION}

Glioblastomas multiforme (GBM) is the most aggressive form of primary brain tumors with their tendency to invade surrounding healthy brain parenchyma, rendering them largely incurable. Despite advanced therapeutic strategies including surgery, radiotherapy and chemotherapy, the average survival time of a GBM patient is less than 16 months [1]. This poor prognosis is attributable to the rapid proliferation and aggressive infiltration of GBM cells. However, the mechanisms underlying GBM diffusion remain unclear. Identification of a causal molecular linkage might contribute to the development of targeted therapy leading to clinical outcome.

Protein kinase $\mathrm{C}$ (PKC) constitutes a family of serine/threonine kinases activated by a variety of external stimuli, such as hormones, growth factors and other membrane receptor ligands, that transduce intracellular signaling through phosphorylation of a large number of protein substrates[2]. Based on their structure and activation characteristics, the PKC family is classified into three subfamilies: classical or conventional PKC isozymes (PKC $\alpha, P K C \beta I, P K C \beta I I$ and $\mathrm{PKC} \gamma)$, nonclassical or novel $\mathrm{PKC}$ isozymes $(\mathrm{PKC} \delta, \mathrm{PKC} \varepsilon, \mathrm{PKC} \eta$ and $\mathrm{PKC} \theta$ ), and atypical $\mathrm{PKC}$ isozymes $(\mathrm{PKC} \zeta, \mathrm{PKC}$ 
and $\mathrm{PKC} \lambda$ )[3]. Given their many cellular roles and highly activation in cancers, not surprisingly a substantial body of evidence has linked PKC isozymes to carcinogenesis and cancer progression in many cancer types, including brain tumors [4-6]. However, since the availability of selective inhibitors of PKC isozymes has been limited, a particular role of specific PKC isozymes in GBM progression has still remained controversial, although specific tools such as siRNA (small interfering RNA) have allowed more detailed analysis of the function of this large family [2]. PKC isozymes have unique roles and differ in cellular functions in both normal and pathological conditions. In fact, the same PKC isozyme can have opposing roles in cancer, presumably due to complexity of their interactions with numerous substrates and the many secondary messenger systems coupled with their cellular and tissuespecific variability $[2,7]$.

In the present work, we demonstrate that among $\mathrm{PKC}$ isoforms, PKC $\delta$ is strongly associated with the invasiveness of GBM cells. Regarding the complexity of downstream signaling pathways, we sought to disentangle the network of PKC $\delta$ signaling components that are associated with GBM cell invasiveness. Importantly, we found that activation of $\mathrm{PKC} \delta$ boosts the invasiveness of GBM cells by stimulating NOTCH2 signaling, which has been considered a novel therapeutic target for GBM treatment $[8,9]$. PKC $\delta$ strengthened $\mathrm{NOTCH} 2$ signaling via SRC/STAT3 activation, ultimately leading to mesenchymal transformation. Moreover, we found that $\mathrm{PKC} \delta$ is activated by a receptor tyrosine kinase c-MET, which has been found to be highly overexpressed in GBM patients and correlated with a median survival [10]. Collectively, our findings suggest that the c-MET/PKC $\delta$ drives to activation of SRC/STAT3/Notch2 signaling axis, implicating a novel therapeutic target to suppress the invasiveness of GBM.

\section{RESULTS}

\section{PKC $\delta$ is a critical contributor to GBM infiltration}

To determine the effect of PKC isozymes on the infiltration of GBM cells, we depleted individual PKC isoforms (PKC $\alpha, \mathrm{PKC} \beta, \mathrm{PKC} \zeta$, and $\mathrm{PKC} \delta$ ) by siRNA in the U87 GBM and patient-derived X01 GBM cells, and analyzed the migration and invasion of GBM cells in matrigel-coated (invasion assay) or uncoated (migration assay) transwells. Notably, knockdown of the isoform $\mathrm{PKC} \delta$ was the most effective in suppressing the migration and invasion of both U87 and patient-derived GBM cells (Fig. 1A). Since migration and invasion in transwells could be underestimated by the relative decrease in the cell number caused by cell cycle arrest or death, we examined cell proliferation and cell death following treatment with PKC $\delta$ siRNA. Knockdown of PKC $\delta$ had no effect on cell proliferation or cell death (Fig. S1A, B), suggesting that migration and invasion assays in transwells were not affected by differential cell proliferation or cell death. To confirm the effect of PKC $\delta$ on invasiveness, we sought to extend our observations to additional GBM cell lines. Consistent with the above data, siRNA-mediated downregulation of PKC $\delta$ also efficiently suppressed the migration and invasion of U373 and T98 GBM cells (Fig. 1B).

To further evaluate the role of $\mathrm{PKC} \delta$, we also examined the invasiveness of U87 GBM cells using 3D culture system in which collagen type I, a common ECM component, and Matrigel, with a composition similar to that of the basement membrane, were mixed and solidified in growth medium. For visualization, U87 GBM cells were transduced with green fluorescence protein (GFP) prior to the assay. Consistent with the above data, treatment with siRNA against PKC $\delta$ markedly decreased infiltration of U87 GBM cells compared to treatment with a control, scrambled siRNA, indicating that $\mathrm{PKC} \delta$ is a critical regulator for GBM cell infiltration (Fig. 1C).

Since mesenchymal traits are correlated with GBM cell invasiveness [11, 12], we next examined whether PKC $\delta$ causes mesenchymal transformation of GBM cells. To this end, we analyzed the mesenchymal cell markers CDH2, VIM, and their regulators SNAI1, SNAI2, ZEB1 and TWIST1, after treatment with PKC $\delta$ siRNA. Depletion of PKC $\delta$ decreased CDH2 and VIM expression as well as that of their regulators SNAI2 and ZEB1 (Fig. 1D, 1E and Fig. S1C). In agreement with this result, siRNA-mediated knockdown of SNAI2 or ZEB1 suppressed the migratory and invasive properties of GBM cells (Fig. S1D). However, treatment with either siRNA against $\mathrm{PKC} \alpha,-\beta$ or $-\zeta$ did not substantially decrease those mesenchymal markers, suggesting a distinctive role of PKC $\delta$ among the isoforms in mesenchymal transformation of GBM cells (Fig. S1E).

To further examine the direct involvement of $\mathrm{PKC} \delta$ in the invasiveness of GBM cells, we next analyzed the effect of PKC $\delta$ overexpression on the migration and invasion of U87 GBM cells. As expected, and in contrast to knockdown, PKC $\delta$ overexpression enhanced the migratory and invasive properties of GBM cells (Fig. $1 \mathrm{~F}, 1 \mathrm{G})$. PKC $\delta$ overexpression also caused an increase in expression of the mesenchymal markers $\mathrm{CDH} 2, \mathrm{VIM}$ and their regulators SNAI2, ZEB1 in GBM cells (Fig. 1H, 1I and Fig. S1F).

To confirm the effect of PKC $\delta$ on the infiltration of GBM cells in vivo, we injected U87 GBM cells $\left(5 \times 10^{4}\right.$ cells) orthotopically into the brains of athymic nude mice after transduction with PKC $\delta$ shRNA. 25 days later, histological staining of brain sections indicated that control shRNA-transduced U87 GBM cells formed tumors that had loosened and infiltrated into normal brain parenchyma, rendering the boundary between normal and tumor tissues indistinguishable (Fig. 1J). In contrast, tumors formed by U87 GBM cells transduced 
A

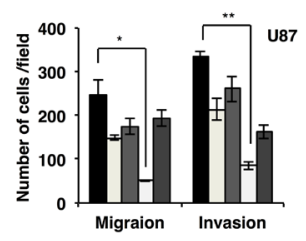

C
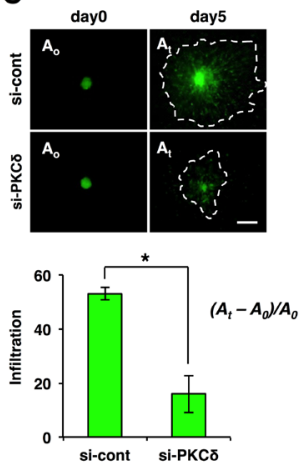

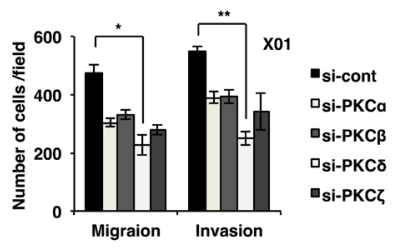

D

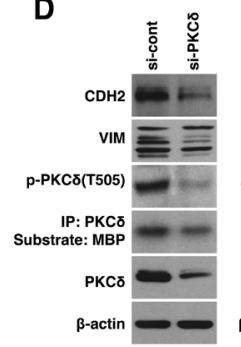

F

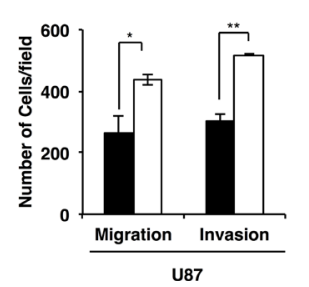

B
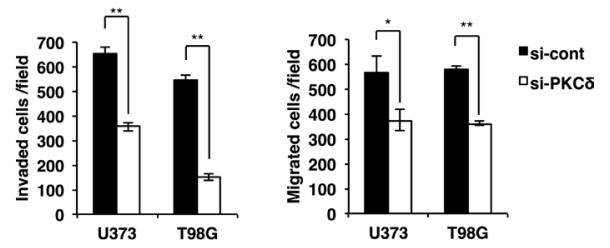

E

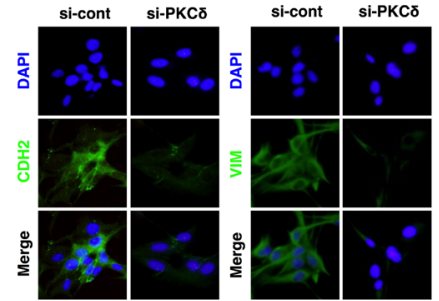

G
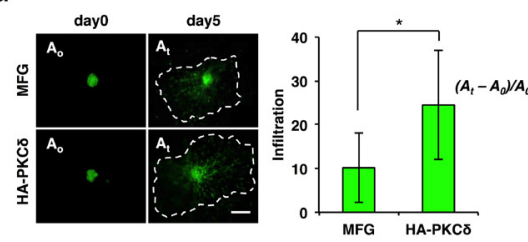

J

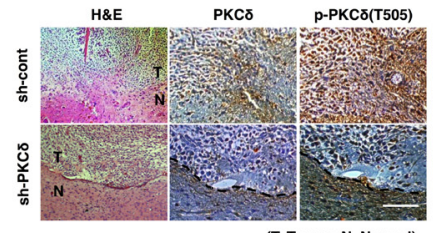

K

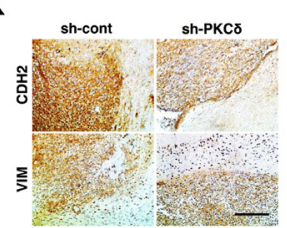

L
H
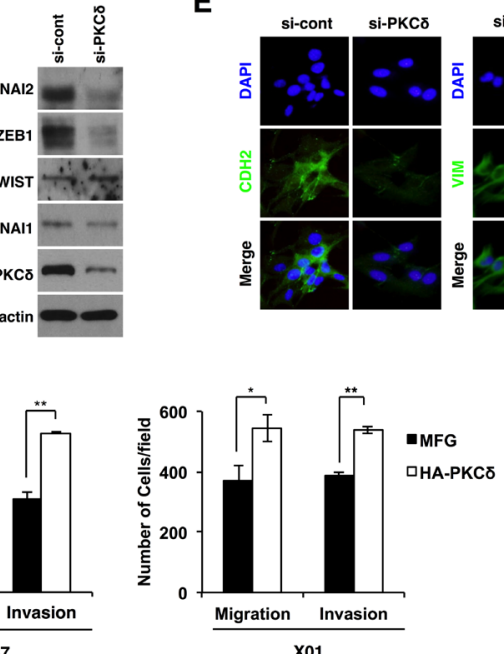

I

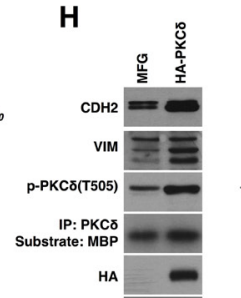

HA

PKC -

$\beta$-actin $=$
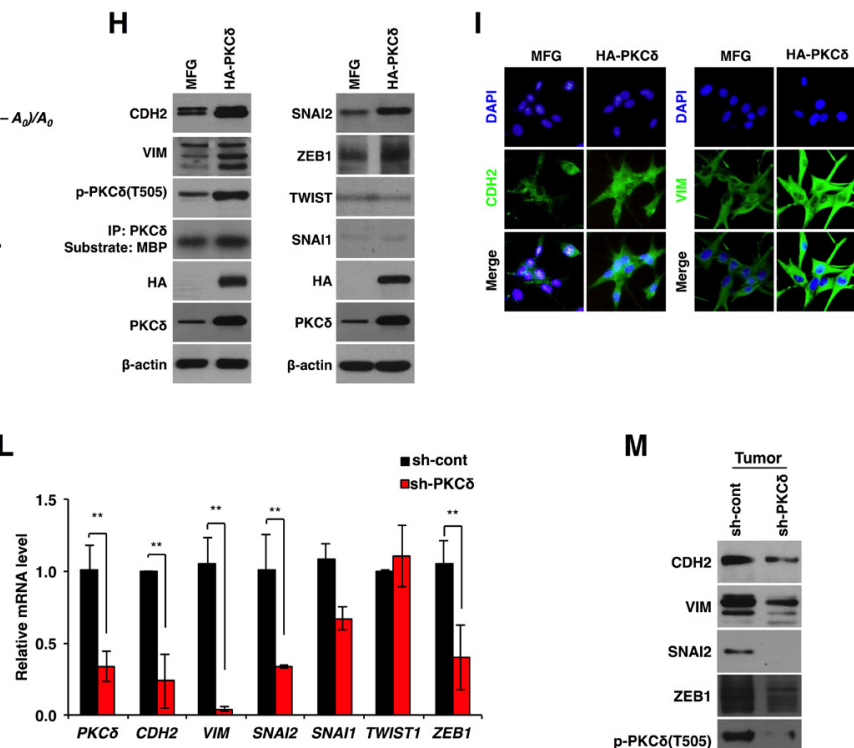

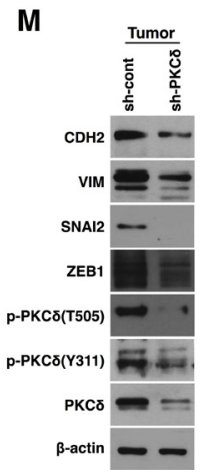

Figure 1: Effect of PKC $\delta$ on infiltration of GBM cells through mesenchymal transformation. A. Migration and invasion assay in GBM cells transfected with control or PKC isoform siRNAs as indicated. B. Migration and invasion assay in GBM cells transfected with control or PKC $\delta$ siRNAs. C. Effect of PKC $\delta$ depletion on infiltration of U87 GBM cells in collagen-based matrix three-dimensional (3D) culture system. Scale bar, $100 \mu \mathrm{m}$. D. Western blot analysis for mesenchymal markers and regulators in U87 GBM cells transfected with control or PKC $\delta$ siRNAs. E. Immunocytochemistry for CDH2 and VIM in U87 GBM cells transfected with control or PKC $\delta$ siRNAs. F. Migration and invasion assay in GBM cells transduced with MFG or HA-PKC $\delta$. G. Effect of PKC $\delta$ on infiltration of U87 GBM cells in collagen-based matrix 3D culture system. Scale bar, $100 \mu \mathrm{m}$. H. Western blot analysis for mesenchymal markers and regulators in U87 GBM cells transduced with MFG or HA-PKC $\delta$. I. Immunocytochemistry for CDH2 and VIM in U87 GBM cells transduced with MFG or HA-PKC $\delta$. J, K. Immunohistochemistry for p-PKC $\delta(\mathrm{J})$, and $\mathrm{CDH} 2$, VIM (K) in orthotopic U87 cell-xenograft tumors. U87 GBM cells were transduced with pSuper or PKC $\delta$ shRNA prior to injection to mice. Scale bar, $200 \mu \mathrm{m}$. L, M. q-RT PCR (L) and Western blot analysis (M) for mesenchymal markers and regulators in the orthotopic xenograft tumors. $\beta$-actin was used for a loading control. *, $P<0.05$ versus control; **, $p<0.01$ versus control. 
with PKC $\delta$ shRNA were relatively intact and dense, and appeared to exhibit a distinct margin. Consistent with in vitro data, shRNA-mediated knockdown of $\mathrm{PKC} \delta$ in vivo decreased the levels of CDH2 and VIM as well as those of SNAI2, SNAI1, and ZEB1 in xenograft mice (Fig. $1 \mathrm{~K}-1 \mathrm{M})$. Taken together, these results suggest that PKC $\delta$ promotes infiltration of GBM cells through mesenchymal transformation.

\section{PKC $\delta$ promotes mesenchymal transformation through activation of SRC and STAT3}

We next sought to determine which intracellular signaling route is activated by $\mathrm{PKC} \delta$ that drives to infiltration of GBM cells. Since AKT, MAPK (mitogenactivated protein kinase), NF- $\kappa \mathrm{B}$ (nuclear factor-kappaB), SRC and STAT (signal transducer and activator of transcription) signaling components are known to be downstream effectors of $\mathrm{PKC} \delta$, we analyzed the activation status of these signaling molecules after treatment with PKC $\delta$ siRNA. Notably, we found that $\mathrm{PKC} \delta$ depletion caused a decrease in SRC Tyr418 phosphorylation and STAT3 Tyr705 and Ser727 phosphorylation, but did not alter activation of AKT, NF- $\kappa \mathrm{B}$ or the MAPKs ERK (extracellular signal-regulated kinase), p38, or JNK (c-Jun N-terminal kinase) (Fig. 2A and Fig. S2A). Knockdown of either SRC or STAT3 did not activate PKC $\delta$, indicating that $\mathrm{PKC} \delta$ is upstream of SRC and STAT3 (Fig. S2B). To further confirm it, PKC $\delta$ was overexpressed in U87 GBM cell line and patient-derived X01 GBM cells and the activation status of SRC and STAT3 was analyzed. In agreement with these observations, the phosphorylation of SRC and STAT3 was enhanced by PKC $\delta$ overexpression (Fig. 2B).

Similar to the effect of $\mathrm{PKC} \delta$, depletion of SRC or STAT3 caused a decrease in migration and invasion of GBM cells in transwells (Fig. 2C, 2D). To confirm the effect, we also examined the invasiveness of GBM cells in 3D culture system after treatment with siRNA against SRC or STAT3. As expected, knockdown of either SRC or STAT3 inhibited the infiltrative properties of GBM cells in this system (Fig. 2E).

To validate the effects of PKC $\delta$ on SRC and STAT3 activation in vivo, we investigated the phosphorylation status of SRC and STAT3 by immunohistochemical analysis of tissue sections of GBM formed from orthotopically injected U87 GBM cells in mice. In line with our in vitro data, we observed that $\mathrm{p}-\mathrm{SRC}$ and p-STAT3 were diminished in tumors formed by $\mathrm{PKC} \delta$ depleted GBM cells compared with tumors formed from scrambled shRNA-transduced GBM cells (Fig. 2F). Immunoblotting analyses conducted in parallel on the same tumor tissues confirmed the immunohistochemistry results (Fig. 2G).

Because our data indicated that $\mathrm{PKC} \delta$ promoted mesenchymal transformation of GBM cells, we next examined whether inhibition of SRC and STAT3 also suppresses mesenchymal transformation. To this end, we analyzed CDH2, SNAI2, and ZEB1 after treatment of GBM cells with siRNA against SRC or STAT3. SRC depletion decreased CDH2 and VIM expression as well as that of their regulators SNAI2 and ZEB1 (Fig. 2H, 2I and Fig. S2C). Similarly, STAT3 depletion also caused a decrease in the levels of these mesenchymal signature proteins (Fig. 2J, 2K and Fig. S2C).

Since we found that SRC and STAT3 were activated by $\mathrm{PKC} \delta$, we next determined the sequence of PKC $\delta$ signal-activation events. Importantly, knockdown of SRC led to a decrease in the p-STAT3, whereas STAT3 depletion did not change the p-SRC level (Fig. 2L, 2M). To further confirm the SRC/STAT3 signaling axis, we treated GBM cells with SRC inhibitor PP2 and analyzed the phosphorylation status of STAT3. Consistently, inhibition of SRC activity attenuated STAT3 phosphorylation (Fig. $\mathrm{S} 2 \mathrm{D})$. These data indicate that $\mathrm{PKC} \delta$ activates SRC, which in turn activates STAT3 to trigger the mesenchymal transformation underlying the infiltrative behavior of GBM cells.

\section{PKCס/SRC/STAT3 signaling contributes to mesenchymal transformation via activation of NOTCH2}

We next examined whether $\mathrm{PKC} \delta$ is involved in NOTCH signaling, which has been found to play an important role in the pathogenesis of GBM [8, 9]. To this end, we examined the expression levels of NOTCH receptors and ligands. We found that siRNA-mediated PKC $\delta$ knockdown decreased levels of transcripts for the NOTCH2 receptor and its ligands JAG1 and -2 (Fig. 3A, 3B and Fig. S3A, B). Consistent with this, immunocytochemical analyses confirmed that $\mathrm{PKC} \delta$ depletion decreased protein levels of NOTCH2 and its ligands JAG1 and -2 (Fig. 3C, 3D). In parallel with these findings, $\mathrm{PKC} \delta$ overexpression increased $\mathrm{NOTCH} 2$ and its ligands JAG1 and -2 (Fig. 3E). However, NOTCH2 depletion did not alter $\mathrm{PKC} \delta$ phosphorylation, indicating that NOTCH2 signaling acts as a downstream effector of PKC $\delta$ (Fig. S3C).

Extending these data, we next examined whether NOTCH2 is associated with infiltration of GBM cells. We found that siRNA-mediated knockdown of NOTCH2 suppressed the migration and invasion of GBM cells in a manner similar to that of PKC $\delta$ knockdown (Fig. 3F and Fig. S3D). Among NOTCH isoforms, NOTCH2 knockdown was the most effective in suppressing GBM cell migration and invasion (data not shown). Since NOTCH signaling is initiated by cytoplasmic cleavage of the $\mathrm{NOTCH}$ intracellular domain (NICD), we also analyzed migration and invasion following treatment with GSI, which inhibits cleavage of the NICD. Consistent with the effect of siRNA, inhibition of $\gamma$-secretase effectively suppressed the 


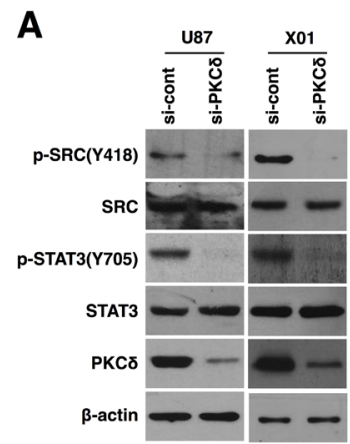

D
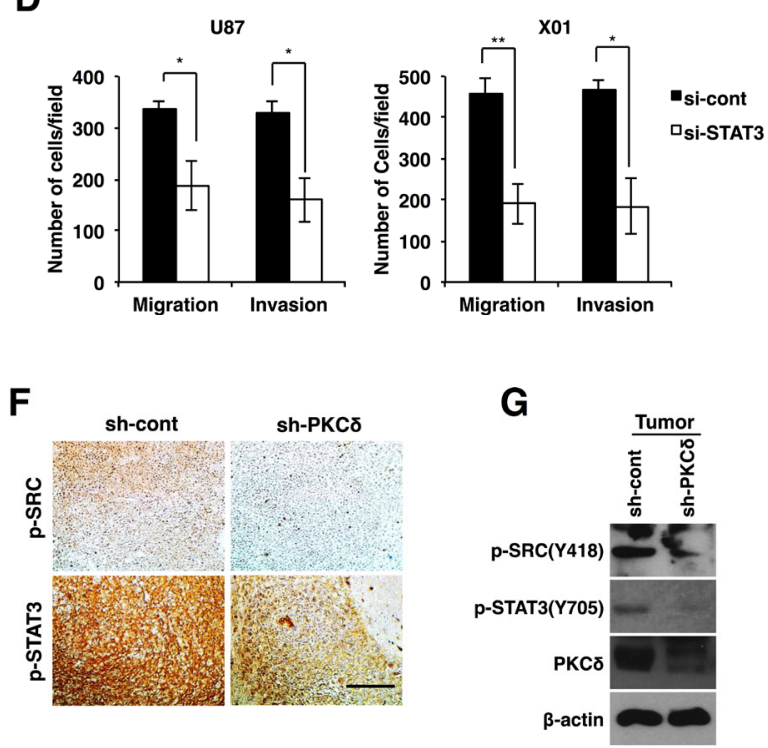
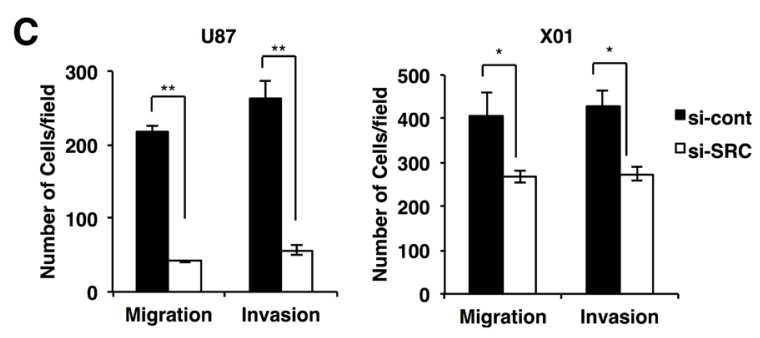

E
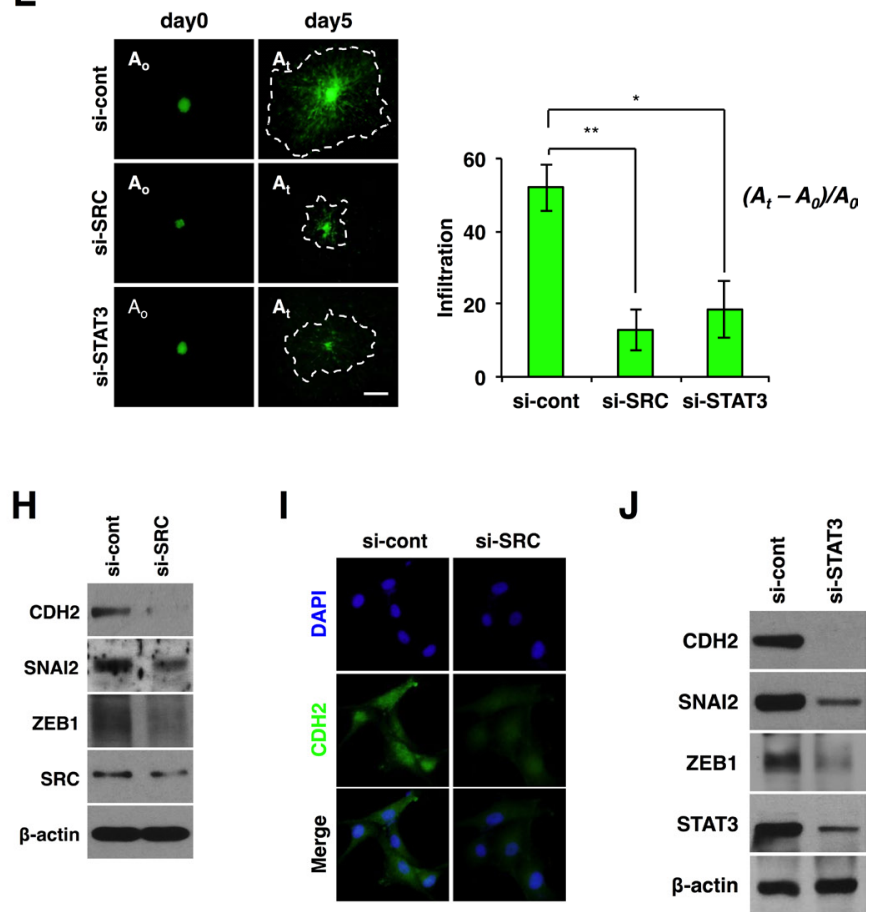
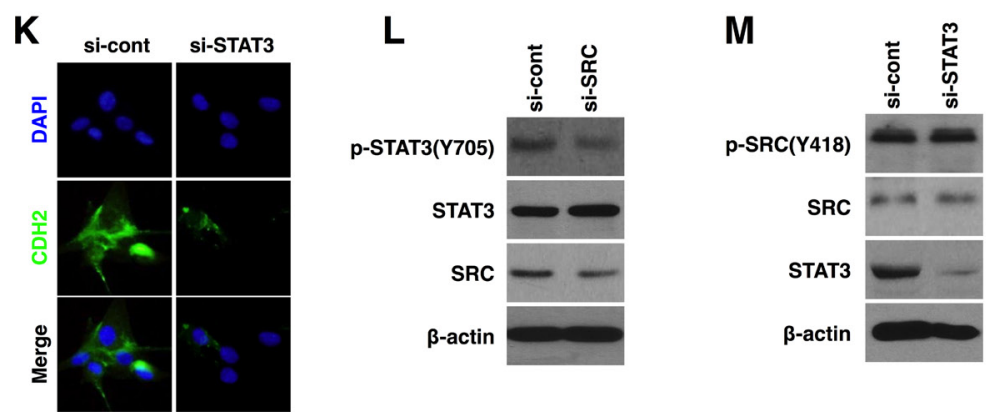

Figure 2: PKC $\delta$ promotes mesenchymal transformation through activation of SRC and STAT3. A, B. Western blot analysis for phosphorylation status of SRC and STAT3 in GBM cells transfected with control or PKC $\delta$ siRNAs (A), or transduced with MFG or HA-tagged PKC $\delta$ (B). C, D. Migration and invasion assay in GBM cells transfected with control or SRC (C), or STAT3 siRNAs (D). E. Infiltration of GBM cells transfected with control siRNAs or siRNAs against SRC or STAT3 in collagen-based matrix 3D culture system. Scale bar, $100 \mu \mathrm{m}$. F, G. Immunohistochemistry (F) and western blot analysis (G) for p-SRC and p-STAT3 in orthotopic U87 GBM cell-xenograft tumors. U87 GBM cells were transduced with control or PKC $\delta$ shRNA prior to orthotopic injection to mice. Scale bar, 200 $\mu \mathrm{m}$. (H, I) Western blot analysis for CDH2, SNAI2 and ZEB1 H., and immunocytochemistry for CDH2 I. in U87 GBM transfected with control or SRC siRNAs. (J, K) Western blot analysis for CDH2, SNAI2 and ZEB1 J., and immunocytochemistry for CDH2 K. in U87 GBM cells transfected with control or STAT3 siRNAs. L. Western blot analysis for p-STAT3 in U87 GBM cells transfected with control or SRC siRNAs. M. Western blot analysis for p-SRC in U87 GBM cells transfected with control or STAT3 siRNAs. $\beta$-actin was used for a loading control. *, $P<0.05$ versus control; **, $p<0.01$ versus control. 
A

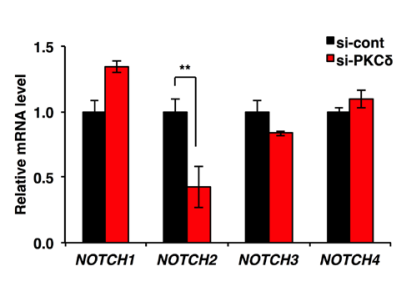

B

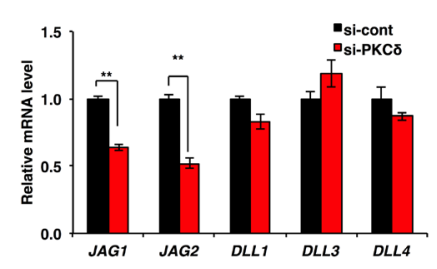

C

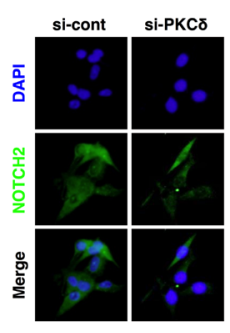

F
D

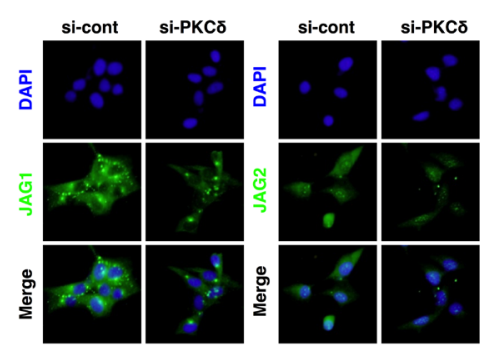

G
E

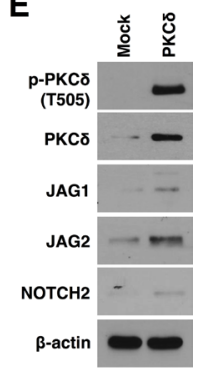

H
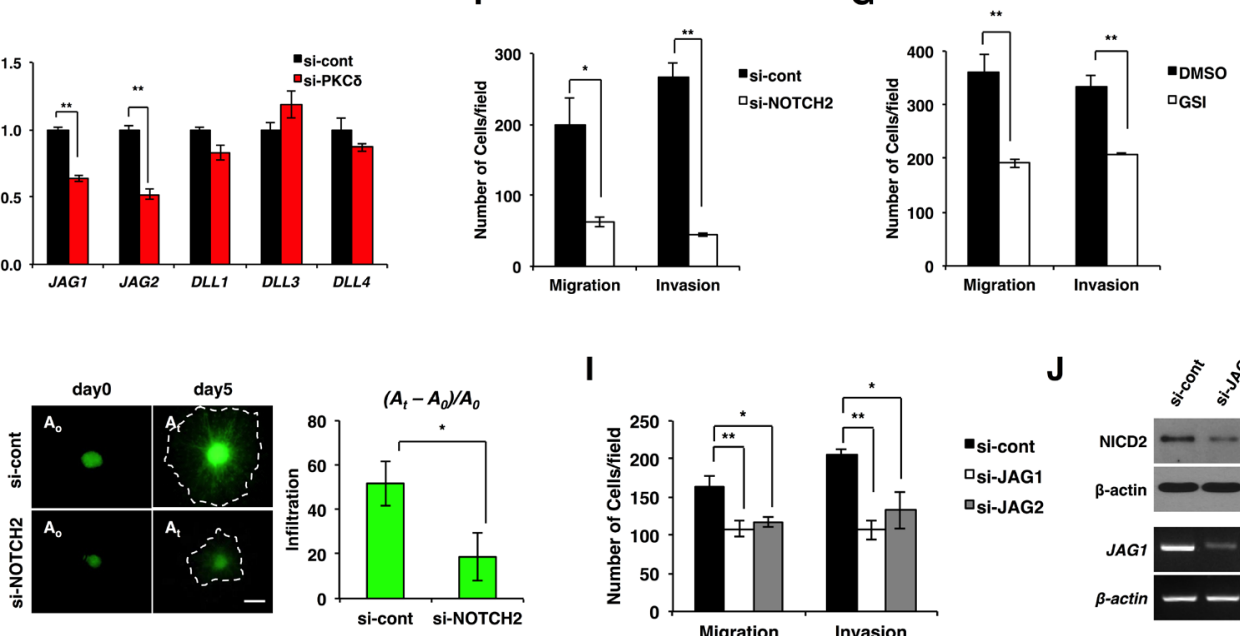

|
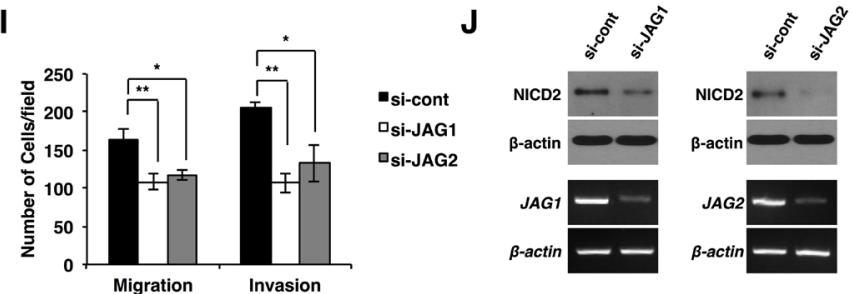

$\mathbf{K}$

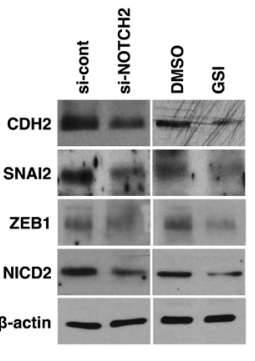

L
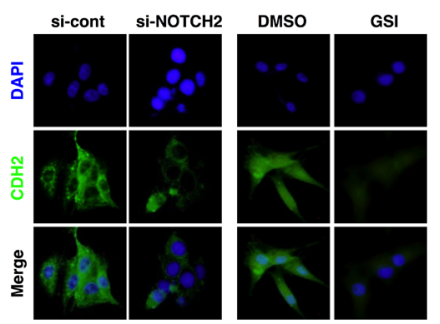

M
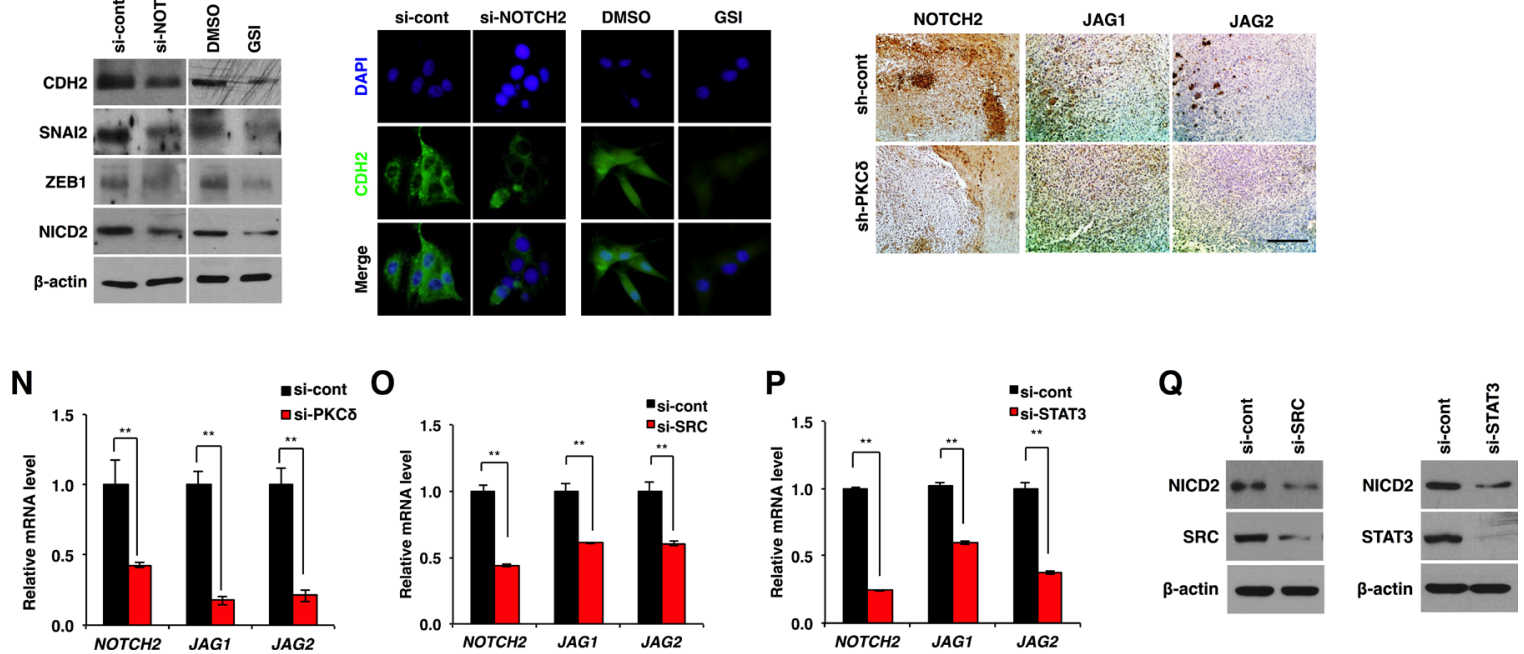

Figure 3: NOTCH2 is required for PKCס-associated mesenchymal transformation. A, B. qRT-PCR for NOTCH isoforms (A) and the ligands (B) in U87 GBM cells transfected with control or PKC $\delta$ siRNAs. C, D. Immunocytochemistry for NOTCH2 (C) and ligands JAG1 and -2 (D) in U87 GBM cells transfected with control or PKC $\delta$ siRNAs. E. Western blot analysis for NOTCH2 and its ligands JAG1 and -2 in U87 GBM cells transduced with MFG or HA-PKC $\delta$. F, G. Migration and invasion assay in U87 GBM cells transfected with NOTCH2 siRNAs (F) or treated with $\gamma$-secretase inhibitor (GSI) (G), as compared to control. H. Infiltration of U87 GBM cells transfected with control or NOTCH2 siRNAs in collagen-based matrix 3D culture system. Scale bar, $100 \mu$ m. I. Migration and invasion assay in U87 GBM cells transfected with control siRNAs or siRNAs against JAG1 or -2. J. Western blot analysis for NICD2 in U87 GBM cells transfected with control siRNAs or siRNAs against JAG1 or -2. K, L. Western blot analysis for CDH2, SNAI2 and ZEB1 (K), and immunocytochemistry for CDH2 (L) in U87 GBM cells transfected with NOTCH2 siRNAs or treated with GSI. M, N. Immunohistochemical staining (M) and qRT-PCR (N) for NOTCH-2, JAG1 and -2 in orthotopic xenograft tumors formed by U87 GBM cells transduced with control (pSuper) or PKC $\delta$ shRNAs. Scale bar, $200 \mu \mathrm{m}$. O, P. qRT-PCR for NOTCH-2, JAG1 and -2 in U87 GBM cells transfected by control siRNAs or siRNAs against SRC (O) or STAT3 (P). Q. Western blot analysis for NICD2 in U87 GBM cells transfected by control siRNAs or siRNAs against SRC or STAT3. $\beta$-actin was used for a loading control. *, $P<0.05$ versus control; **, $p<0.01$ versus control. 
migratory and invasive properties of GBM cells (Fig. 3G). To validate the effect of NOTCH2, we also examined the invasiveness of GBM cells in the 3D culture system after treatment with NOTCH2 siRNA. As expected, NOTCH2 depletion markedly inhibited the infiltration of GBM cells (Fig. 3H). Treatment with siRNA against NOTCH ligands JAG1 or -2 also suppressed the migration and invasion of GBM cells (Fig. 3I), an effect that might be attributable to a decrease in the levels of NICD2 (Fig. 3J). Since PKC $\delta$ promoted infiltration of GBM cells through mesenchymal transformation, we next examined whether NOTCH2 is involved in mesenchymal transformation as a downstream effector of PKC $\delta$. As was observed with PKC $\delta$ siRNA, treatment with NOTCH2 siRNA or with GSI caused a decrease in $\mathrm{CDH} 2$, SNAI2, and ZEB1 expression (Fig. 3K, 3L and Fig. S3E). We further confirmed the regulation of $\mathrm{NOTCH} 2$ by $\mathrm{PKC} \delta$ in in vivo condition. By immunohistochemical staining we observed that $\mathrm{NOTCH} 2$, JAG1 and -2 were diminished in tumors formed by U87 GBM cells transduced with PKC $\delta$ shRNA compared with control tumors formed from scrambled shRNA-transduced U87 GBM cells (Fig. 3M). In agreement with this data, qRT-PCR analysis also revealed that depletion of PKC $\delta$ decreased the transcripts of NOTCH2, JAG1 and -2 in the orthotopic xenograft tumors (Fig. 3N).
We next examined whether NOTCH2 can be increased by SRC and STAT3, whose activities in turn are increased by $\mathrm{PKC} \delta$. Importantly, down-regulation of either SRC or STAT3 caused a decrease in the NOTCH2 receptor and its ligands JAG1 and -2 (Fig. 3O-3Q and Fig. $\mathrm{S} 3 \mathrm{~F}, \mathrm{G})$. Taken together, these results suggest that PKC $\delta$ promotes mesenchymal transformation through activation of the SRC/STAT3/NOTCH2 signaling axis.

\section{PKC $\delta$ is a downstream effector of c-MET in GBM}

c-MET and epidermal growth factor receptor (EGFR) are well-known tyrosine receptor kinases that are coexpressed in multiple cancers, including GBM [13, 14]. Since these tyrosine receptor kinases are closely associated with the malignant phenotypes of GBM, we examined whether PKC $\delta$ is an effector of these signaling pathways. Notably, siRNA-mediated knockdown of c-MET significantly decreased the phosphorylation of PKC $\delta$, whereas depletion of EGFR or variant EGFRvIII had no such effect (Fig. 4A and Fig. S4A). In line with the data presented above, c-MET depletion attenuated the migration and invasion of GBM cells (Fig. 4B and Fig. S4B). Consistently, treatment with c-MET siRNA also

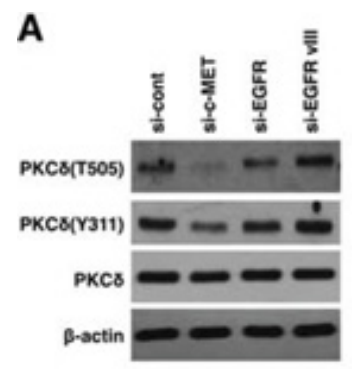

B

E

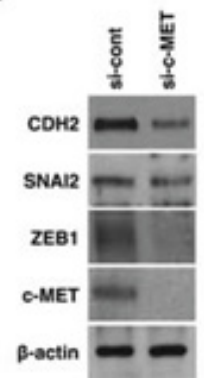

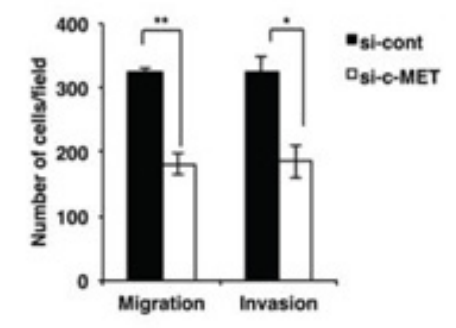

$\mathbf{F}$

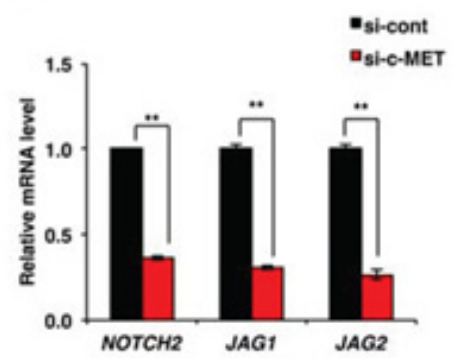

C
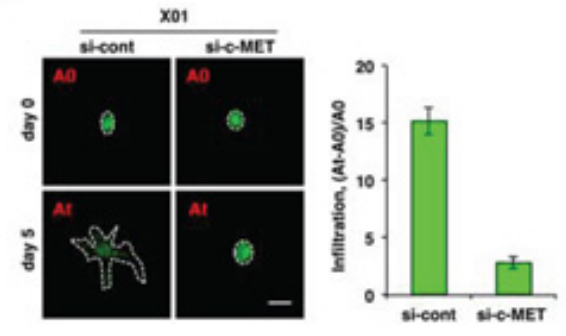

G

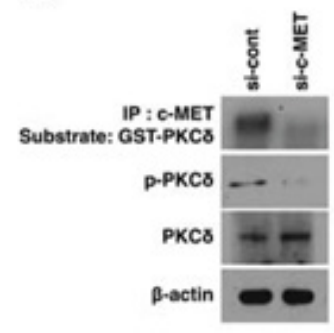

D

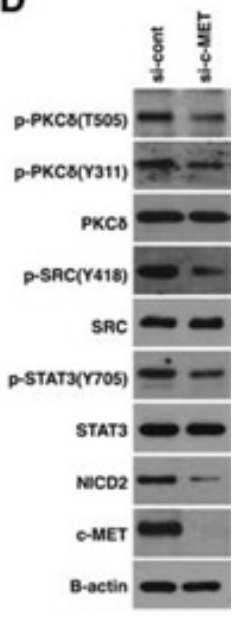

Figure 4: PKC $\delta$ is activated by c-MET. A. Western blot analysis for activation status of PKC $\delta$ in U87 GBM cells transfected with control, c-MET, EGFR or EGFRvIII siRNAs. B. Migration and invasion assay in U87 GBM cells transfected with control or c-MET siRNAs. C. Infiltration of X01 GBM cells transfected with control or c-MET siRNAs in collagen-based matrix 3D culture system. Scale bar, $100 \mu \mathrm{m}$. D, E. Western blot analysis for activation status of PKCס, SRC, STAT3 and NOTCH2 (D) or for CDH2, SNAI2 and ZEB1 (E) in U87 GBM cells transfected with control or c-MET siRNAs. F. qRT-PCR for NOTCH-2, JAG1 and -2 in U87 GBM cells transfected by control or c-MET siRNAs. G. Kinase assay of immunoprecipitated c-MET using GSC-PKC $\delta$ as a substrate and western blot analysis for p-PKC $\delta$ in U87 GBM cells transfected with control or c-MET siRNAs. $\beta$-actin was used for a loading control. *, $P<0.05$ versus control; **, $p<0.01$ versus control. 
mitigated the infiltration of patient-derived X01 GBM cells in 3-D spheroid (Fig. 4C).

Also in accord with these results, c-MET knockdown caused a decrease in the activation of SRC, STAT3 and $\mathrm{NOTCH} 2$, which are downstream effectors of PKC $\delta$ (Fig. 4D and Fig. S4C). In agreement, c-MET depletion caused a decrease in CDH2, SNAI2, and ZEB1 expression as observed in $\mathrm{PKC} \delta$ or NOTCH2 knockdown (Fig. 4E and Fig. S4D). In addition, c-MET depletion decreased the transcript levels of NOTCH2, JAG1 and -2 (Fig. 4F and Fig. S4E). We next examined whether PKC $\delta$ is a direct substrate of c-MET kinase. Importantly, c-MET kinase assay revealed that $\mathrm{c}-\mathrm{MET}$ could phosphorylate $\mathrm{PKC} \delta$, implicating $\mathrm{PKC} \delta$ as a direct substrate of c-MET (Fig. $4 \mathrm{G})$. To further confirm this finding, we also increased c-MET activation directly by treatment with hepatocyte growth factor (HGF), a well-known ligand for c-MET, and examined the changes in $\mathrm{PKC} \delta$ phosphorylation and $\mathrm{NOTCH} 2$ levels. In agreement with the above data, we observed that $\mathrm{PKC} \delta$ phosphorylation and NOTCH2 levels are proportionally increased in HGF concentrationdependent manner (Fig. S4F). Collectively, our results suggest that PKC $\delta$ is a downstream effector of c-MET and boosts infiltration of GBM cells through SRC/STAT3/ NOTCH2 signaling axis.

To evaluate the potential relevance of PKC $\delta$ as a clinical target, we next compared the levels of PKC $\delta$ in tissues of human GBM with that in normal brain counterparts. Importantly, immunohistochemical analyses revealed that PKC $\delta$ is highly expressed in GBM compared to normal tissues (Fig. 5A). The phosphorylation status was also higher in GBM than in normal tissue. To further confirm this, we compared PKC $\delta$ activity in 20 cases GBM patient tissues with that in non-neoplastic brain tissues. The results obtained were in agreement, showing that $\mathrm{PKC} \delta$ activities were higher in most GBM than in non-neoplastic tissues (Fig. 5B). Since we found that PKC $\delta$ contributes to the infiltration of GBM cells through NOTCH2 signaling, we also examined the p-PKC $\delta$ and NOTCH2 levels in patient GBM tissues. By immunohistochemistry, we found that the p-PKC $\delta$ is co-localized with NICD2 in almost cells of GBM patient tissues (Fig. 5C). Since PKC $\delta$ boosts infiltration of GBM cells in vitro and is highly activated in human
A

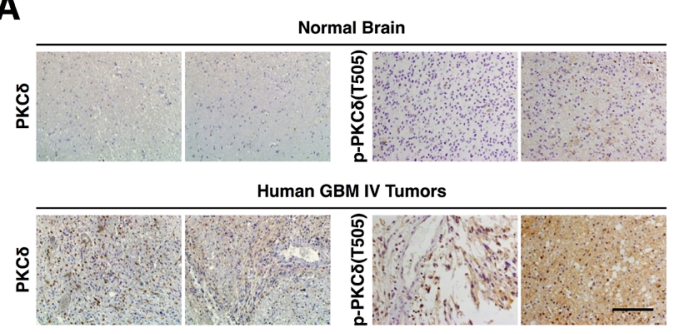

C

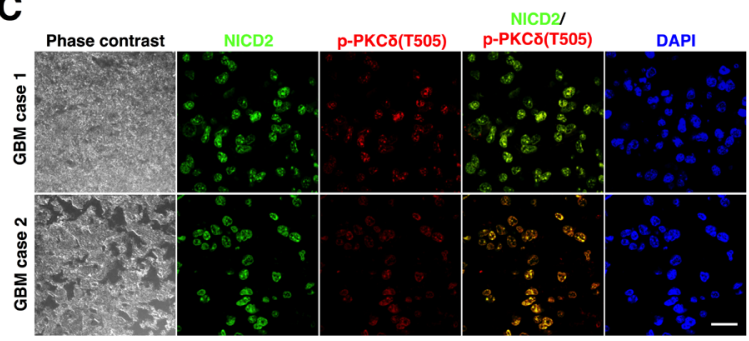

D

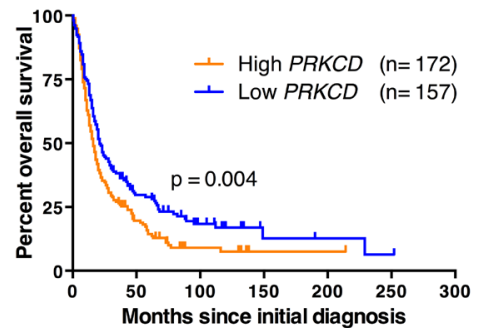

B

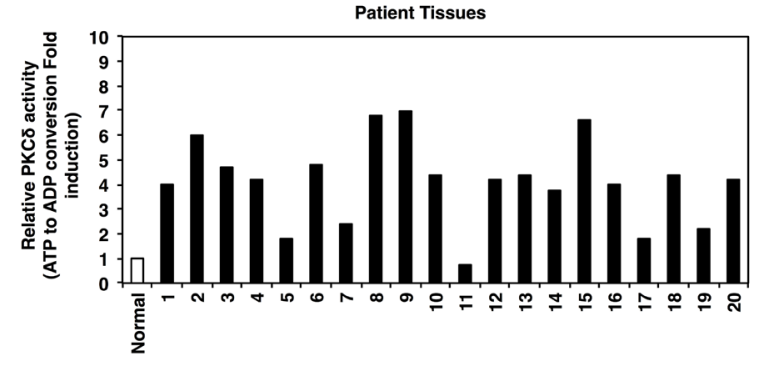

E

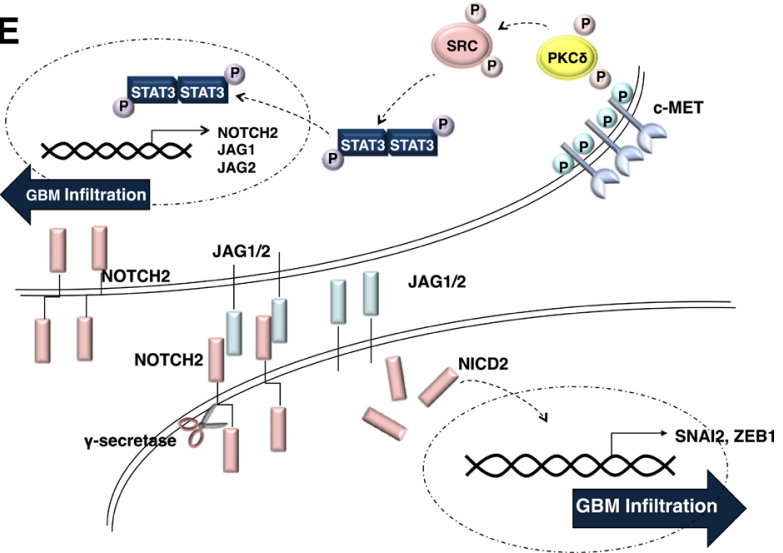

Figure 5: Clinical relevance of PKC $\delta$ in GBM patients. A. Immunohistochemistry for PKC $\delta$ and p-PKC $\delta$ in human normal brain tissues and GBM patients $(n=30)$. Scale bar, $200 \mu \mathrm{m}$. B. PKC $\delta$ kinase activity in normal brain tissue and 20 cases of human GBM patients. C. Immunohistochemistry for co-staining of PKC $\delta$ and NICD2 in human GBM. Scale bar, $100 \mu$ m. D. Kaplan-Meier survival curves of high and low levels of PKC $\delta$ in human brain tumor patients with REMBRANDT database. E. Schematic model illustrating the PKC $\delta$ associated signaling pathways leading to infiltration of GBM. 
GBM tissues, we next evaluated whether PKC $\delta$ levels in human brain tumor correlated with patient survival. Evaluation of data in REMBRANDT database revealed that expression levels of PKC $\delta$ in human brain tumors are inversely correlated with the patient survival (Fig. 5D). In contrast, however, expression levels of other PKC isoforms (PKC $\alpha$ and $-\beta$ ) were proportional to the patient survival time, emphasizing the differential role of PKC $\delta$ from the isoforms (Fig S5). Although these retrospective data cannot determine whether PKC $\delta$ is an independent predictor of survival, these data suggest that $\mathrm{PKC} \delta$ is a negative prognostic factor for human glioma patients. Taken altogether, these results suggest that PKC $\delta$ likely contributes to the infiltration of GBM cells in vivo through the c-MET/PKC $\delta / \mathrm{SRC} / \mathrm{STAT} 3 / \mathrm{NOTCH} 2$ signaling axis as it does in vitro (Fig. 5E).

\section{DISCUSSION}

Despite recent advances in anticancer therapeutic strategies, including surgery, chemotherapy and radiotherapy, the clinical outcomes for GBM patients have not shown a proportional improvement. This dismal prognosis is attributable to GBM invasiveness. Thus, identifying the pivotal molecular mediators of GBM infiltration is a prerequisite for developing targeted therapies to improve clinical outcomes of GBM patients.

In this study, we found that among PKC isoforms, PKC $\delta$ contributes to GBM cell invasiveness. Notably, PKC $\delta$ knockdown effectively suppressed migration and invasion of GBM cells, whereas PKC $\delta$ overexpression enhanced infiltration. Moreover, $\mathrm{PKC} \delta$ promoted invasiveness of GBM cells through mesenchymal transformation. Since down-regulation of PKC $\delta$ has been associated with tumor promotion, it has been previously thought that PKC $\delta$ functions as a tumor suppressor [1517]. However, in keeping with our observation, many recent studies have also reported that $\mathrm{PKC} \delta$ contributes to tumor progression $[18,19]$. These contrasting observations highlight the complexity of $\mathrm{PKC} \delta$ signaling pathways and suggest that the different cellular responses could be caused by activation of different sets of downstream effectors. Following this notion, we sought to identify PKC $\delta$ downstream effectors that are associated with GBM cell infiltration. Importantly, we found that PKC $\delta$ increased phosphorylation of SRC, which in turn activated STAT3 and, ultimately, NOTCH2 signaling, leading to mesenchymal transformation.

Previous studies have strongly implicated the non-receptor tyrosine kinase SRC in the development, maintenance, progression, and invasiveness of several human cancers, including brain cancers [20]. Despite the finding that the SRC gene is not amplified or mutated, the activity of the corresponding protein was found to be higher in GBM compared to normal brain tissues. Moreover, the activation of SRC is known to be closely associated with poor prognosis of GBM [21, 22]. Similarly, no genetic alterations leading to STAT3 overexpression have been identified. However, approximately $70 \%$ of human cancers display persistent STAT3 activation, causing induction of oncogenes [23-25]. In keeping with this notion, our finding that STAT3 can be activated by $\mathrm{PKC} \delta$ could explain the aberrant activation of STAT3 in GBM.

Our study also showed that PKC $\delta$-enhanced STAT3 activation causes an increase in NOTCH2 signaling. By previous studies, NOTCH signaling has correlation with GBM progression [8, 26]. In particular, Chen et al. suggested that $\mathrm{NOTCH} 2$ is the predominant $\mathrm{NOTCH}$ receptor that contributes to the growth of GBM [27]. Consistent with these previous studies, we found that $\mathrm{PKC} \delta$ increases expression of the $\mathrm{NOTCH} 2$ receptor and its ligands JAG1 and -2 through activation of SRC/STAT3. Collectively, our findings suggest that $\mathrm{PKC} \delta$ is responsible for the persistent activation of NOTCH2 as well as SRC and STAT3, thereby contributing to GBM progression.

The tyrosine kinase c-MET has been reported to promote tumor formation and resistance to DNA damage, and expand the GBM stem-like cell population. Accordingly, numerous small molecule inhibitors targeting this pathway are at advanced stages of clinical development [28-30]. Notable in this context, we found that c-MET increases the activation of PKC $\delta$. In agreement with this finding, c-MET inhibition decreased the activation of SRC and STAT3 and the expression of NOTCH2 receptor and its ligands JAG1 and -2 , an effect similar to $\mathrm{PKC} \delta$ depletion.

In summary, we have identified PKC $\delta$ downstream effectors that are associated with the GBM cell invasiveness. Importantly, $\mathrm{PKC} \delta$ promoted mesenchymal transformation of GBM cells through activation of SRC/ STAT3/NOTCH2 signaling. We also showed that PKC $\delta$ is activated by c-MET, linking the PKC $\delta$ signaling node to c-MET, a target of therapeutic agents at an advanced stage of clinical development. Collectively, our findings implicate the c-MET/PKCס/SRC/STAT3/NOTCH2 signaling axis as a potential therapeutic target in GBM treatment.

\section{MATERIALS AND METHODS}

\section{Cell culture}

U87, U373 and T98G GBM cells were obtained from the Korean Cell Line Bank (KCLB, Seoul, Korea). The patient-derived X01 GBM cells were established from acutely resected human tumor tissues obtained with written informed consent from a 68-year-old woman with GBM. U87, U373, and X01 GBM cells were cultured in Dulbecco's modified Eagle Medium (Gibco, Korea, Seoul) and T98G cells were cultured in Minimum 
Essential Medium (Gibco), containing 1\% penicillin and streptomycin, supplemented with $10 \%$ heat-inactivated fetal bovine serum. For visualization, U87 GBM cells were labeled by transduction with MSCV-GFP that was kindly provided from Hee-Yong Chung (Department of Medicine, Hanyang University).

\section{Chemical reagents and antibodies}

Polyclonal antibodies to $\mathrm{PKC} \delta$, vimentin (VIM), TWIST11, SNAI1 (also known as SNAI1), SNAI2 (also

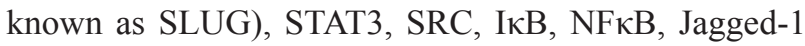
(JAG1), Jagged-2 (JAG2) and CDH2 (also known as $\mathrm{N}$-cadherin) were purchased from Santa Cruz (Santa Cruz, CA, USA). Polyclonal antibodies to $\mathrm{p}-\mathrm{PKC} \delta$ (Y311), phospho-STAT3 (Y705), AKT, p-AKT (S473), p-AKT (T308), ERK1/2, p-ERK1/2 (T202/204), Cleaved NOTCH1, JNK, p-P38, and monoclonal antibodies to $\mathrm{HA}, \mathrm{NOTCH} 3$ and NOTCH4 were purchased from Cell Signaling Technology (Beverly, MA, USA). Polyclonal antibodies to phospho- PKC $\delta$ (T505), activated NOTCH2 and p-SRC(Y418) were purchased from Abcam and polyclonal antibody to ZEB1 was purchased from Sigma. Monoclonal antibody to $\mathrm{p}-\mathrm{JNK}$ was purchased from BD. Anti-Human NOTCH-2 Intracellular Domain Antigen Affinity-purified Polyclonal Antibody was purchased from R\&D systems. $\gamma$-secretase inhibitor (GSI) was purchased from Calbiochem (San Diego, CA, USA).

\section{Western blot analysis}

Cell lysates were prepared by extracting proteins with lysis buffer [40 mM Tris- $\mathrm{HCl}$ (pH 8.0), $120 \mathrm{mM}$ $\mathrm{NaCl}, 0.1 \%$ Nonidet-P40] supplemented with protease inhibitors. Proteins were separated by SDS-PAGE, and transferred to a nitrocellulose membrane (Amersham, Arlington Heights, IL, USA). The membrane was blocked with 5\% non-fat dry milk in Tris-buffered saline, and incubated with primary antibodies overnight at $4{ }^{\circ} \mathrm{C}$. Blots were developed with a peroxidase-conjugated secondary antibody, and proteins visualized by enhanced chemiluminescence (ECL) procedures (Amersham), using the manufacturer's protocol.

\section{Invasion and migration assays}

For invasion assay, the cells $\left(2 \times 10^{4}\right.$ cells/well $)$ were loaded in the upper well of the transwell chamber (8- $\mu \mathrm{m}$ pore size; Corning Glass, Seoul, Korea) that was precoated with $10 \mathrm{mg} / \mathrm{ml}$ growth factor-reduced matrigel (BD Biosciences, Seoul, Korea) on the upper side of the chamber, with the lower well filled with $0.8 \mathrm{ml}$ of DMEM. After incubation for $48 \mathrm{~h}$ at $37^{\circ} \mathrm{C}$, non-migrated cells on the upper surface of the filter were removed with a cotton swab, and migrated cells on the lower surface of the filter were fixed and stained with a Diff-Quick kit and photographed. Invasiveness was determined by counting cells in five microscopic fields per well, and the extent of invasion was expressed as an average number of cells per microscopic field. Cells were imaged by phase contrast microscopy (Leica Microsystems, Bannockburn, IL, USA). For migration assay, we performed the same procedure using the same chambers with control inserts that contained the same type of membrane but without the Matrigel coating. Infiltration of GBM cells was also analyzed in 3D spheroid cultures. Collagen type I (2 mg/ $\mathrm{ml}$ ) and matrigel (11\%) were deposited in individual chamber slides and polymerized in growth medium. GFPexpressing U87 GBM spheroid was then seeded on the collagen-based matrix and the collagen-based matrix was covered on it. After $48 \mathrm{~h}$, infiltration of GBM cells was analyzed under microscope.

\section{Immunocytochemistry}

Cells were fixed with 4\% paraformaldehyde and permeabilized with $0.1 \%$ Triton X-100 in PBS. Following cell fixation, cells were incubated with the appropriate primary antibodies in a solution of PBS with $1 \%$ bovine serum albumin and $0.1 \%$ Triton $\mathrm{X}-100$ at $4{ }^{\circ} \mathrm{C}$ overnight. Antibodies used were as follows: -CDH2 (rabbit polyclonal antibody, 1:200), -VIM (rabbit polyclonal antibody, 1:200), -activated NOTCH2 (rabbit polyclonal antibody, 1:200), -JAG1 (rabbit monoclonal antibody, 1:200), and -JAG2; rabbit polyclonal antibody, 1:200). Cells were visualized using anti-rabbit or antimouse Alexa Flour 488 (Molecular Probes). Nuclei were counterstained using 4,6-diamidino-2-phenylindole (DAPI; Sigma, St Louis, MO, USA). Stained cells were visualized with a fluorescencemicroscope (Olympus IX71, Seoul, Korea).

\section{Transfection}

Small interfering RNA (siRNAs) or DNA plasmids were introduced into cells using a Microporator-mini (Digital Bio-Technology, Seoul, Korea) according to the procedure recommended by the manufacturer. Cells were harvested at $48 \mathrm{~h}$ for subsequent experiments. All siRNAs were purchased from Genolution Pharmaceuticals (Seoul, Korea). A validated shRNA (Mbiotech, Seoul, Korea) was cloned into pSuper vector.

\section{Transduction}

The full length of PKC $\delta$ was cloned into retroviral vector pMFG. For viral production, 293T cells were transfected with retroviral vector $\mathrm{pMFG}$ or $\mathrm{pMFG-HA-}$ $\mathrm{PKC} \delta$, or pMSCV-GFP using the lipofectamine 2000 (Invitrogen, Carlsbad, CA, USA). $48 \mathrm{~h}$ after the transfection, viral supernatant was collected and passed through a $0.45 \mu \mathrm{m}$ filter, and the viral supernatant was 
then used for transduction with supplementation of $8 \mu \mathrm{g} /$ $\mathrm{ml}$ polybrene (Sigma, St. Louis, MO, USA).

\section{Reverse transcription PCR}

Total RNA was isolated manually using the Trizol (Invitrogen Carlsbad, CA, USA). All qRT-PCR was performed using KAPA SYBR FAST qPCR kit from KAPA Biosystems (Wilmington, MA, USA), according to the manufacturer's recommendations. Reactions were carried out in Rotor Gene Q (Qiagene, Seoul, Korea) and results were expressed as fold change calculated by the $\triangle \triangle \mathrm{Ct}$ method relative to the control sample. GAPDH was used as an internal normalization control.

\section{Immune complex kinase assay}

Proteins in cell lysates were immunoprecipitated with primary antibody at $4^{\circ} \mathrm{C}$ for $4 \mathrm{~h}$. The immunoprecipitates were washed with kinase reaction buffer (50 mM HEPES, pH 7.5, $10 \mathrm{mM} \mathrm{MgCl}_{2}, 1 \mathrm{mM}$ dithiothreitol, $2.5 \mathrm{mM}$ EGTA, $1 \mathrm{mM} \mathrm{NaF}, 0.1 \mathrm{mM}$ $\mathrm{Na}_{3} \mathrm{VO}_{4}$ and $10 \mathrm{mM}$ glycerophosphate) and then resuspended in $20 \mu \mathrm{l}$ of kinase reaction buffer. The kinase assay was initiated by adding $20 \mu \mathrm{l}$ of kinase reaction buffer, containing $10 \mu \mathrm{g}$ of substrate and $2 \mu \mathrm{Ci}$ of $\left[\gamma_{-}{ }^{32} \mathrm{P}\right]$ ATP (Valent Pharmaceuticals International, Laval, QC, Canada). The reactions were carried out at $30^{\circ} \mathrm{C}$ for 30 minutes and terminated by adding SDS sample buffer. The reaction products were analyzed by SDS-PAGE and autoradiography. Also, the activity of $\mathrm{PKC} \delta$ was measured by PKC kinase activity kit (Enzo Life Science, Seoul, Korea). Human GBM patient tissues were kindly provided by Prof. Kang in Severance Hospital. Prior informed consents were obtained from the GBM sample donors.

\section{Animal experiments}

X01 GBM cells $\left(5 \times 10^{4}\right.$ cells/mouse $)$ were orthotopically injected into athymic BALB/c nude mice (6 weeks old, KBT Oriental, Charles River Grade, Tosu, Saga, Japan) through the burr hole in to the right striatum at the coordinates of $2.0 \mathrm{~mm}$ lateral to the midline, 3.0 $\mathrm{mm}$ in vertical and anterior-posterior at the zero point to the bregma ( $n=5 /$ group). Mice were sacrificed around 3.5 weeks and the mouse brains were sectioned at the center of burr hole and tumor sizes were analyzed following hematoxylin and eosin staining. Mice were housed in microisolator cages under sterile conditions and lighting, temperature, and humidity were controlled centrally. This study was approved by the Institutional Animal Care and Use Committee of Yonsei University.

\section{Immunohistochemistry}

Mice were sacrificed and tumor tissues were fixed in formalin for the preparation of paraffin sections.
Paraffin-embedded tissue sections were deparaffinized in xylene, 95,90 and $70 \%$ ethanol, followed by phosphatebuffered saline (PBS). Epitopes were unmasked with 20 $\mathrm{mg} / \mathrm{ml}$ proteinase $\mathrm{K}$ in PBS with $0.1 \%$ Triton $\mathrm{X}-100$. Sections were stained with hematoxylin and eosin or immunostained with the $\mathrm{PKC} \delta$, p-PKC $\delta$, VIM, $\mathrm{CDH} 2$, p-SRC, p-STAT3, NOTCH2, JAG1, JAG2 antibodies. After washing in PBS, 1:200 dilution of biotinylated goat anti-rabbit IgG or anti-mouse IgG antibody in blocking solution was applied to the sections. After washing in PBS, $\mathrm{ABC}$ reagent was applied to the sections. Color reaction was performed with 3,3' diaminobenzidine (Vector Laboratories, Burlingame, CA, USA) and slides were washed with PBS. After counterstaining with hematoxylin and clearing with graded ethanol series and xylene, the sections were mounted with Canada balsam. Observation and photography were conducted by IX71 microscope (Olympus, Seoul, Korea).

\section{Tissue array}

The levels of $\mathrm{PKC} \delta, \mathrm{p}-\mathrm{PKC} \delta$ and $\mathrm{NOTCH} 2$ were analyzed using tissue array containing 30 human GBMs and 2 normal brain tissues (ISU ABXIS, Seoul, Korea).

\section{Kaplan-meier survival analysis}

The National Cancer Institute's Repository for Molecular Brain Neoplasia Data (REMBRANDT, http:// www.betastasis.com/glioma/rembrandt, accessed June 2015) was evaluated for correlations between clinical outcome/survival and PRKCD gene expression in human brain tumor biopsies. For REMBRANDT, "high expression" is defined as upper than threshold 7.4; "low expression" is defined as lower than the threshold. Similarly, patient survival curves were also obtained for other isoforms PRKCA and PRKCB.

\section{Statistical analysis}

All experimental data are reported as means and the error bars represent the experimental standard errors. Statistical analyses were performed using parametric Student t-tests.

\section{ACKNOWLEDGMENTS}

We thank to prof. Hee-Yong Chung (Department of Medicine, Hanyang University) for providing retroviral vectors. This work was supported by the National Research Foundation (NRF) and Ministry of Science, ICT and Future Planning, Korean government, through its National Nuclear Technology Program (NRF-2012M2B2B1055639 and NRF2014M2A2A7045072). 


\section{CONFLICTS OF INTEREST}

The authors declare no conflict of interest.

\section{REFERENCES}

1. Stupp R, Mason WP, van den Bent MJ, Weller M, Fisher B, Taphoorn MJ, Belanger K, Brandes AA, Marosi C, Bogdahn U, Curschmann J, Janzer RC, Ludwin SK, et al. Radiotherapy plus concomitant and adjuvant temozolomide for glioblastoma. N Engl J Med. 2005; 352:987-996.

2. Mochly-Rosen D, Das K, Grimes KV. Protein kinase C, an elusive therapeutic target? Nat Rev Drug Discov. 2012; 11:937-957.

3. Mackay HJ, Twelves CJ. Targeting the protein kinase C family: are we there yet? Nat Rev Cancer. 2007; 7:554-562.

4. Mandil R, Ashkenazi E, Blass M, Kronfeld I, Kazimirsky G, Rosenthal G, Umansky F, Lorenzo PS, Blumberg PM, Brodie C. Protein kinase Calpha and protein kinase Cdelta play opposite roles in the proliferation and apoptosis of glioma cells. Cancer Res. 2001; 61:4612-4619.

5. Assender JW, Gee JM, Lewis I, Ellis IO, Robertson JF, Nicholson RI. Protein kinase $\mathrm{C}$ isoform expression as a predictor of disease outcome on endocrine therapy in breast cancer. J Clin Pathol. 2007; 60:1216-1221.

6. Choi PM, Tchou-Wong KM, Weinstein IB. Overexpression of protein kinase C in HT29 colon cancer cells causes growth inhibition and tumor suppression. Mol Cell Biol. 1990; 10:4650-4657.

7. Basu A, Pal D. Two faces of protein kinase Cdelta: the contrasting roles of PKCdelta in cell survival and cell death. TheScientificWorldJournal. 2010; 10:2272-2284.

8. Lino MM, Merlo A, Boulay JL. Notch signaling in glioblastoma: a developmental drug target? BMC medicine. 2010; $8: 72$.

9. Fan X, Khaki L, Zhu TS, Soules ME, Talsma CE, Gul N, Koh C, Zhang J, Li YM, Maciaczyk J, Nikkhah G, Dimeco F, Piccirillo S, Vescovi AL, Eberhart CG. NOTCH pathway blockade depletes CD133-positive glioblastoma cells and inhibits growth of tumor neurospheres and xenografts. Stem Cells. 2010; 28:5-16.

10. Kong DS, Song SY, Kim DH, Joo KM, Yoo JS, Koh JS, Dong SM, Suh YL, Lee JI, Park K, Kim JH, Nam DH. Prognostic significance of c-Met expression in glioblastomas. Cancer. 2009; 115:140-148.

11. Mikheeva SA, Mikheev AM, Petit A, Beyer R, Oxford RG, Khorasani L, Maxwell JP, Glackin CA, Wakimoto H, Gonzalez-Herrero I, Sanchez-Garcia I, Silber JR, Horner PJ, et al. TWIST1 promotes invasion through mesenchymal change in human glioblastoma. Mol Cancer. 2010; 9:194.

12. Kaur H, Phillips-Mason PJ, Burden-Gulley SM, KerstetterFogle AE, Basilion JP, Sloan AE, Brady-Kalnay SM. Cadherin-11, a marker of the mesenchymal phenotype, regulates glioblastoma cell migration and survival in vivo. Mol Cancer Res. 2012; 10:293-304.

13. Birchmeier C, Birchmeier W, Gherardi E, Vande Woude GF. Met, metastasis, motility and more. Nat Rev Mol Cell Biol. 2003; 4:915-925.

14. Puri N, Salgia R. Synergism of EGFR and c-Met pathways, cross-talk and inhibition, in non-small cell lung cancer. J Carcinog. 2008; 7:9.

15. Lu Z, Hornia A, Jiang YW, Zang Q, Ohno S, Foster DA. Tumor promotion by depleting cells of protein kinase C delta. Mol Cell Biol. 1997; 17:3418-3428.

16. Black JD. Protein kinase C-mediated regulation of the cell cycle. Front Biosci. 2000; 5:D406-423.

17. Hernandez-Maqueda JG, Luna-Ulloa LB, Santoyo-Ramos $\mathrm{P}$, Castaneda-Patlan MC, Robles-Flores M. Protein kinase $\mathrm{C}$ delta negatively modulates canonical Wnt pathway and cell proliferation in colon tumor cell lines. PLoS One. 2013; 8:e58540.

18. Mauro LV, Grossoni VC, Urtreger AJ, Yang C, Colombo LL, Morandi A, Pallotta MG, Kazanietz MG, Bal de Kier Joffe ED, Puricelli LL. PKC Delta (PKCdelta) promotes tumoral progression of human ductal pancreatic cancer. Pancreas. 2010; 39:e31-41.

19. Chen Z, Forman LW, Williams RM, Faller DV. Protein kinase $\mathrm{C}$-delta inactivation inhibits the proliferation and survival of cancer stem cells in culture and in vivo. BMC Cancer. 2014; 14:90.

20. Nakada M, Kita D, Watanabe T, Hayashi Y, Teng L, Pyko IV, Hamada J. Aberrant signaling pathways in glioma. Cancers. 2011; 3:3242-3278.

21. Du J, Bernasconi P, Clauser KR, Mani DR, Finn SP, Beroukhim R, Burns M, Julian B, Peng XP, Hieronymus H, Maglathlin RL, Lewis TA, Liau LM, et al. Bead-based profiling of tyrosine kinase phosphorylation identifies SRC as a potential target for glioblastoma therapy. Nat Biotechnol. $2009 ; 27: 77-83$

22. de Groot J, Milano V. Improving the prognosis for patients with glioblastoma: the rationale for targeting Src. J Neurooncol. 2009; 95:151-163.

23. Zammarchi F, de Stanchina E, Bournazou E, Supakorndej $\mathrm{T}$, Martires K, Riedel E, Corben AD, Bromberg JF, Cartegni L. Antitumorigenic potential of STAT3 alternative splicing modulation. Proc Natl Acad Sci U S A. 2011; 108:17779-17784.

24. Brantley EC, Benveniste EN. Signal transducer and activator of transcription-3: a molecular hub for signaling pathways in gliomas. Mol Cancer Res. 2008; 6:675-684.

25. Catlett-Falcone R, Landowski TH, Oshiro MM, Turkson J, Levitzki A, Savino R, Ciliberto G, Moscinski L, Fernandez-Luna JL, Nunez G, Dalton WS, Jove R. Constitutive activation of Stat3 signaling confers resistance to apoptosis in human U266 myeloma cells. Immunity. 1999; 10:105-115. 
26. Hovinga KE, Shimizu F, Wang R, Panagiotakos G, Van Der Heijden M, Moayedpardazi H, Correia AS, Soulet D, Major T, Menon J, Tabar V. Inhibition of notch signaling in glioblastoma targets cancer stem cells via an endothelial cell intermediate. Stem Cells. 2010; 28:1019-1029.

27. Chen J, Kesari S, Rooney C, Strack PR, Chen J, Shen H, $\mathrm{Wu} \mathrm{L}$, Griffin JD. Inhibition of notch signaling blocks growth of glioblastoma cell lines and tumor neurospheres. Genes Cancer. 2010; 1:822-835. doi: 10.1177/1947601910383564
28. Gherardi E, Birchmeier W, Birchmeier C, Vande Woude G. Targeting MET in cancer: rationale and progress. Nat Rev Cancer. 2012; 12:89-103.

29. Comoglio PM, Giordano S, Trusolino L. Drug development of MET inhibitors: targeting oncogene addiction and expedience. Nat Rev Drug Discov. 2008; 7:504-516.

30. Appleman LJ. MET signaling pathway: a rational target for cancer therapy. J Clin Oncol. 2011; 29:4837-4838. 